\section{ECCOMAS}

Proceedia
COMPDYN 2021

$8^{\text {th }}$ ECCOMAS Thematic Conference on Computational Methods in Structural Dynamics and Earthquake Engineering M. Papadrakakis, M. Fragiadakis (eds.) Streamed from Athens, Greece, 28 - 30 June 2021

\title{
EXPERIMENTAL AND NUMERICAL INVESTIGATION OF A MASONRY MODEL BUILDING SUBJECTED TO DYNAMIC BASE EXCITATIONS
}

\author{
Stefania Demosthenous ${ }^{1}$ and Milton Demosthenous ${ }^{2}$ \\ ${ }^{1}$ Civil Engineer, MSc Student, Frederick University, Nicosia, Cyprus \\ st006796@stud.fit.ac.cy \\ ${ }^{2}$ Dr. Civil Engineer, Professor, Frederick University, Nicosia, Cyprus \\ eng.dm@frederick.ac.cy
}

\begin{abstract}
Many research efforts are continued nowadays around the world to validate numerical tools for masonry structures using at the same time results from experimental works. The present paper belongs in these efforts. At the first stage, this paper deals with the design of a simple masonry building in prototype scale (1:1) including earthquake resistance design. After that, the same structure was also designed in scale 1:10 in order to have the same distribution of stresses under vertical and earthquake loadings, the same level of tensile stresses gravity loadings at the critical zones and the same modes of vibrations under dynamic loadings. From this point of view, it was assumed that this model building in scale 1:10 can develop the same structural behavior with the corresponding prototype. Therefore, this model building in scale 1:10 was constructed and tested using the shaking table of Frederick University. During these tests, the acceleration of the base excitation and the acceleration response of the structure were recorded. Using these measurements from the case of $0.3 g$ response acceleration, the max. dynamic loadingof the model was estimated by multiply the response acceleration with the mass of the model. This load wasapplied to the anumerical model with surface finite elements and structural analysis was completed. By the evaluation of the numerical results using Mohr-Coulomb failure criterion, the locations and the type of damages were specified which founded out in a good correlation with the observed damages during the experimental tests. Finally, the same cases of loadings were used for the structural analysis of the prototype structure as well the same procedure for the evaluation of the numerical results. These results developed by the prototype model are correlated with those from the numerical model of the experimental model and discussed.
\end{abstract}

Keywords:Masonry, finite elements, shaking table, numerical simulations, failure criterion 


\section{INTRODUCTION}

The protection of the ancient monuments and historical structures is in the main interest for more than 100 years. In order to protect them from bad and catastrophic interventions, international chapters and relevant codes have been adopted and they are in practice in various countries. The documentation of these structures, as the first stage of the works for their protection, includes the structural analysis of them under vertical, seismic and other cases of loadings with the main scope the assessment and evaluation of their existing capacity. At the second stage, one more structural analysis must be completed to examine their capacity for the suggested intervention scheme. However, it is well known that the majority of monumental and historical structures are masonry structures, consisted by stones or bricks which are arranged in various formations and connected with mortars. Therefore, the masonry is a synthetic and inhomogeneous material. In addition to that, the masonry can be characterized as orthotropic and brittle material. On the other hand, the masonry structures are consisted by 2D and 3D structural elements such as walls, piers, arches, vaults, cross vaults and domes having a global behavior during earthquakes much deferent than that of contemporary structures.

For all these reasons, the simulation and the structural analysis of masonry structures is a very complicated procedure. In the past, many techniques were suggested based on many assumptions and with many questions about the accuracy of the results from these methods. The same problems are existing also for the design of new masonry structures, as described by the EC6 (EN1996).The last 40 years, the used methods for the simulation and structural analysis of masonry structures are based on the Finite Element Method (FEM) utilizing computer software. At the first period the 2D models of structures were used simulating the structural elements with linear elements. Approximately, after 1990 the surface finite elements are the most common used elements for the simulation of masonry structures and more recently the solid elements.

However, many research efforts are continued nowadays around the world to validate numerical tools for masonry structures using at the same time results from experimental works. These works use various experimental methods for the testing of materials, masonry walls and models of masonry building structures studied and tested with compressive machines, lateral static or cycling loadings on a reaction frame and using a shaking table to produce dynamic and earthquake base excitations of studied models. In parallel to the experimental tests, various numerical techniques are used, utilizing software of finite elements to simulate the experimental models and study them under the same loading conditions such as those used during experimental investigation. Through this procedure and by the correlation of experimental and numerical results the numerical tools are calibrated and after that they are used for extended numerical and parametric investigations $[1,2,3,4]$.

Following the previous examples and for the same scope, an extended research effort has been established at the Laboratory of Mechanics of Frederick University including testing of materials, experimental tests on models of masonry structures and numerical simulations. The present paper, at the first stage, deals with the design, the construction and testing on the shaking table of a masonry model structure in scale 1:10 [5]. At the second stage numerical simulations and structural analyses of the experimental model was completed using various levels of seismic actions as recorded during the test. The results from structural analyses were evaluated using Mohr-Coulomb failure criterion and the estimated locations of failures are correlated with those observed during the experimental tests. At last, but not least, the same procedure of structural analysis was developed for the corresponding prototype structure (scale 1:1) and the results are correlated with those from the numerical model of the experimental model in scale 1:10 and discussed. 


\section{DESIGN AND CONSTRUCTION OF THE EXPERIMENTAL MODEL}

\subsection{Mechanical properties of the materials}

A usual limestone for the construction of monumental and historical structures in Cyprus was used for the construction of the model structure. This stone belong to the Pachna Geological Formation (located at the Tochni area) and was supplied by the Tochni Quarries in units with dimensions of $0.04 \mathrm{~m} \times 0.03 \mathrm{~m} \times 0.02 \mathrm{~m}$ as required for the construction of the model structure in scale 1:10. A lime/sand ratio 1:4 was used for the lime-mortar mixture that was used for bonding the bricks using the thin sand produced from crashing of the Tochni's stone. The dimensions of the timber used for the roof beams were $0.009 \mathrm{mx} 0.019 \times 0.45 \mathrm{~m}$.

An extended experimental sequence of tests was performed on the stones, mortar, masonry units and timber, in order to define the mechanical properties of these materials. Three compressive tests of model stone/brick were performed in order to find its compressive strength (fcb) and its modulus of elasticity (E). Table 1 summarizes these tests for each specimen. The compressive strength of mortar was founded out $\mathrm{fcm}=0.303 \mathrm{Mpa}$. In addition, three compressive tests of masonry triplets were performed in order to find the compressive strength of masonry wall (fwc) and the modulus of elasticity (E) (table 2). Apart from compressive tests, shear stress tests were also performed in order to identify the shear strength without compression (fws)of the masonry wall (table 3). The masonry tensile strength (fwt) was assume to be equal to the shear strength. These properties were used for the simulation, structural analysis and evaluation of numerical results for both, the prototype building structure (scale 1:1) and the experimental model (scale 1:10).

\begin{tabular}{ccc}
\hline STONE 4cm X 3cm X 2cm & $\mathrm{fbc}(\mathrm{MPa})$ & $\mathrm{E}_{\mathrm{b}}(\mathrm{MPa})$ \\
\hline SPECIMEN1 (S1) & 49.46 & 874.67 \\
SPECIMEN2 (S2) & 48.24 & 867.77 \\
SPECIMEN3 (S3) & 43.7 & 769.73 \\
Average & 47.13 & 837.39 \\
\hline
\end{tabular}

Table 1: Mechanical characteristics of model stones $4 \mathrm{~cm} \times 3 \mathrm{~cm}$ x $2 \mathrm{~cm}$

\begin{tabular}{ccc}
\hline WALL & fwc $(\mathrm{MPa})$ & E $(\mathrm{MPa})$ \\
\hline TRIPLET 1 (T1) & 14.52 & 880.17 \\
TRIPLET 2 (T2) & 15.7 & 639.91 \\
TRIPLET 3 (T3) & 21.96 & 13.83 \\
Average & 17.393 & 511.303 \\
\hline
\end{tabular}

Table 2: Mechanical characteristics of masonry wall

\begin{tabular}{cc}
\hline TRIPLET & $f w s(M P \alpha)$ \\
\hline T1 & 0.08 \\
T2 & 0.1 \\
T3 & 0.08 \\
Average & 0.087 \\
\hline
\end{tabular}

Table 3: Shear testing results of the masonry wall 


\subsection{Design of the prototype masonry building in scale $1: 1$ and the experimental model in scale 1:10}

At first stage a single storey masonry building was designed with dimensions of those of typical traditional houses as build before and until very early of the $20^{\text {th }}$ century in Cyprus [5]. The architectural design of such houses was usually consisted by an open plan type of space with dimensions $4.0 \mathrm{mx} 7.0 \mathrm{~m}$ and a height of approximately $3.0 \mathrm{~m}$. Two door openings with a width of $1.4 \mathrm{~m}$ are presented at the center of the larger dimension of the plan, while the thickness of the masonry wall is $0.4 \mathrm{~m}$. The two opposite large walls are connected at the roof level with timber beams supporting a traditional horizontal roof system covered by soil materials. The structural and earthquake resistance design of this building was completed according to the provisions of EN-1996 (EC6) and EN-1998 (EC8) and the corresponding National Annexes of Cyprus [5]. For that, the same materials properties (stone, mortar, masonry \&timber) as used for the construction of the experimental model in scale 1:10 were used .

After that, the same structure was also designed in scale 1:10 and constructed (fig. 1). As can be seen, additional masses were attached at the roof level according to basic rules for the design of experimental models in small scaling. Through this effort the final design of model structure was defined in order to have similar distribution of stresses under vertical and earthquake loadings, similar level of stresses at the critical areas and the similarshapes of the predominant modes of vibrations under dynamic loadings. From this point of view, it is assumed that this model building in scale 1:10 can develop the same structural behavior with the corresponding prototype. The correlation of the first three modes of the prototype structure (scale 1:1) and the model one in scale 1:10 are presented in figure 2. As can be seen there is a good agreement between the two models.
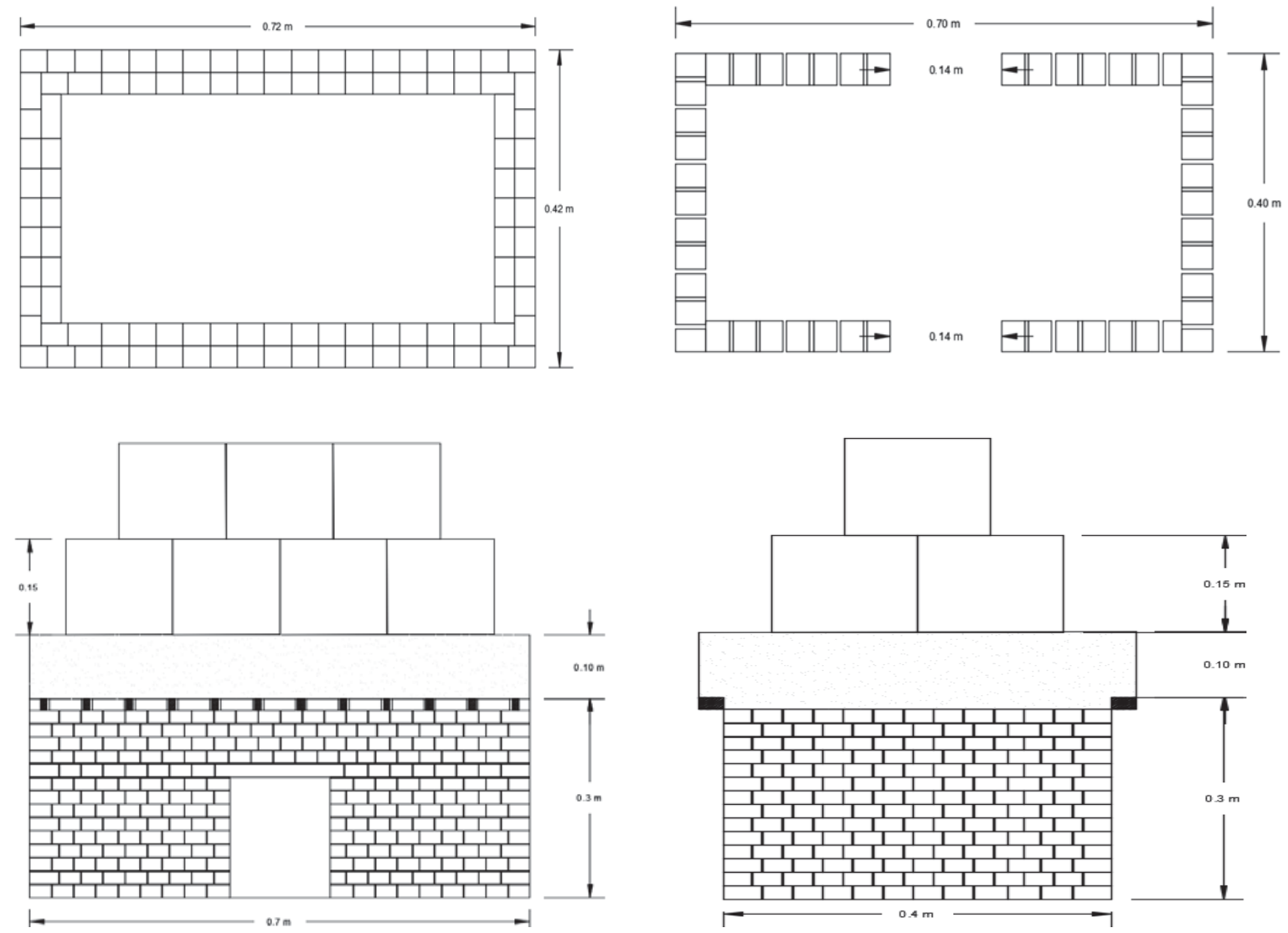

Figure 1: Drawings with the dimensions of the experimental model in scale 1:10 


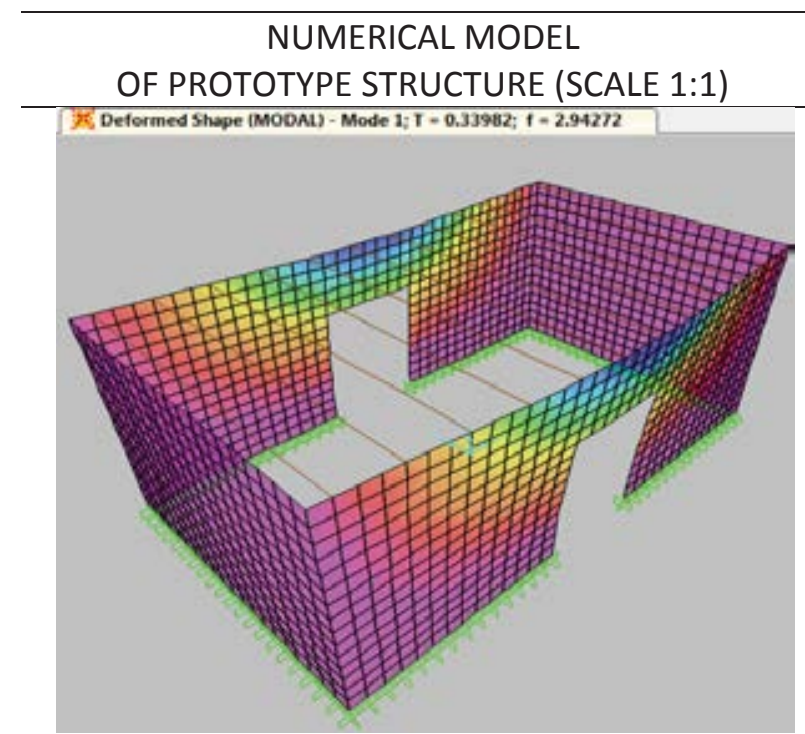

MODE 1 (1st mode in N-S direction)
NUMERICAL MODEL

OF EXPERIMENTAL MODEL(SCALE 1:10)

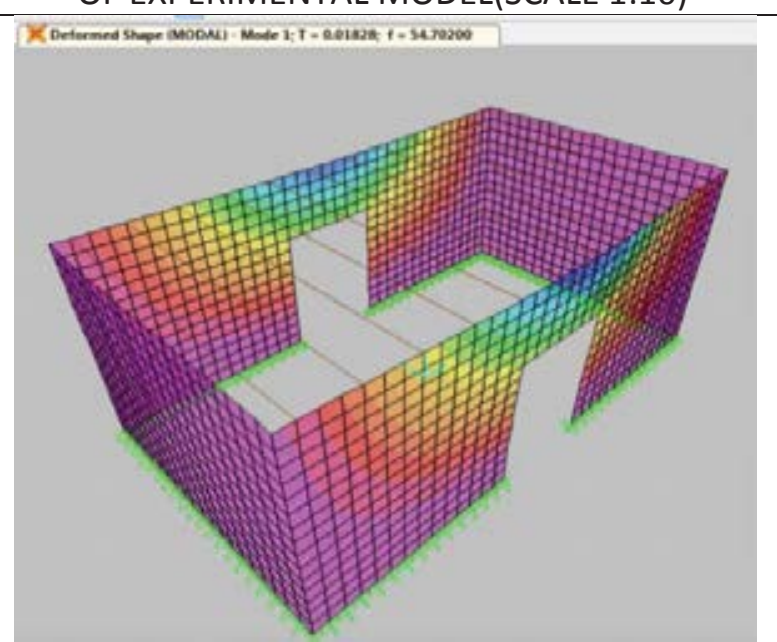

MODE 1 (1st mode in N-S direction)

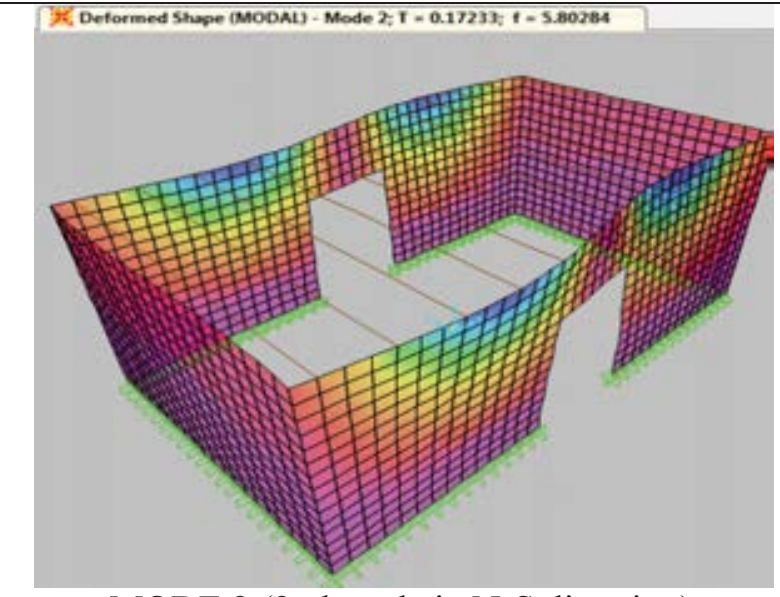

MODE 2 (2nd mode in N-S direction)

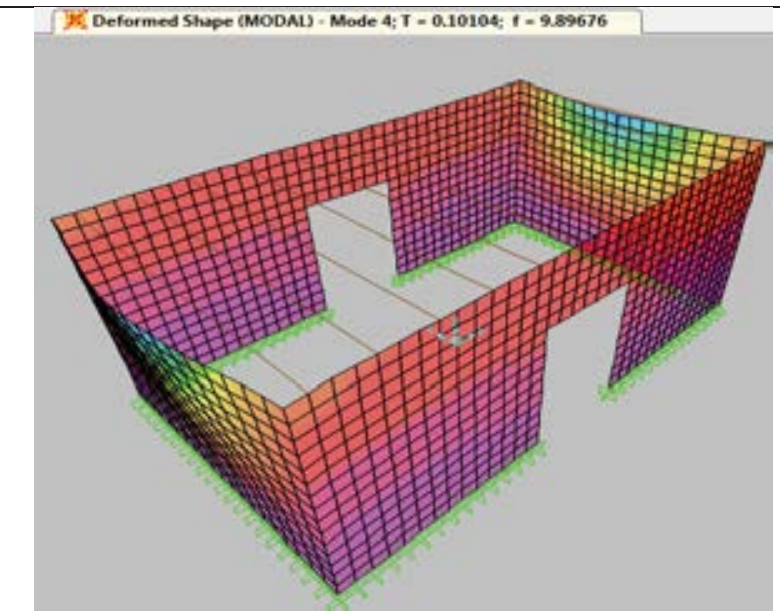

MODE 3 (1st mode in E-W direction)

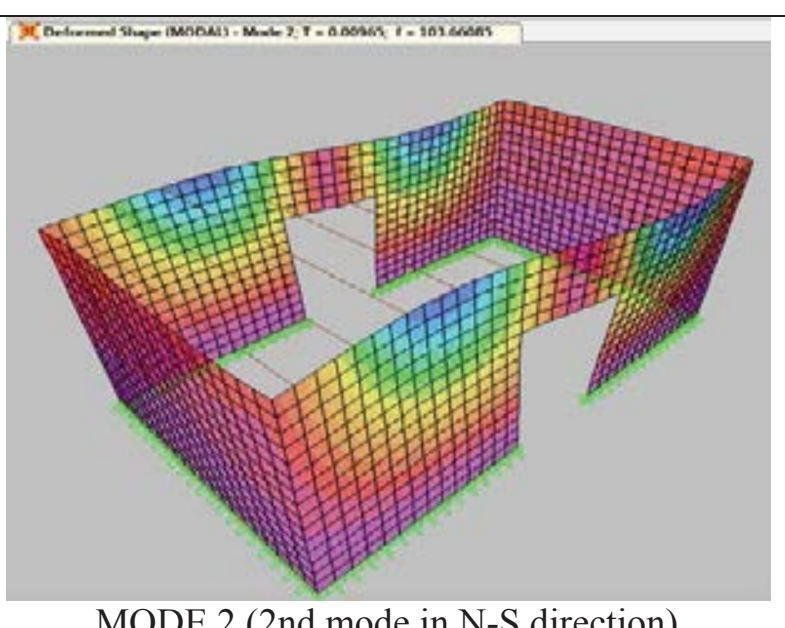

MODE 2 (2nd mode in N-S direction)

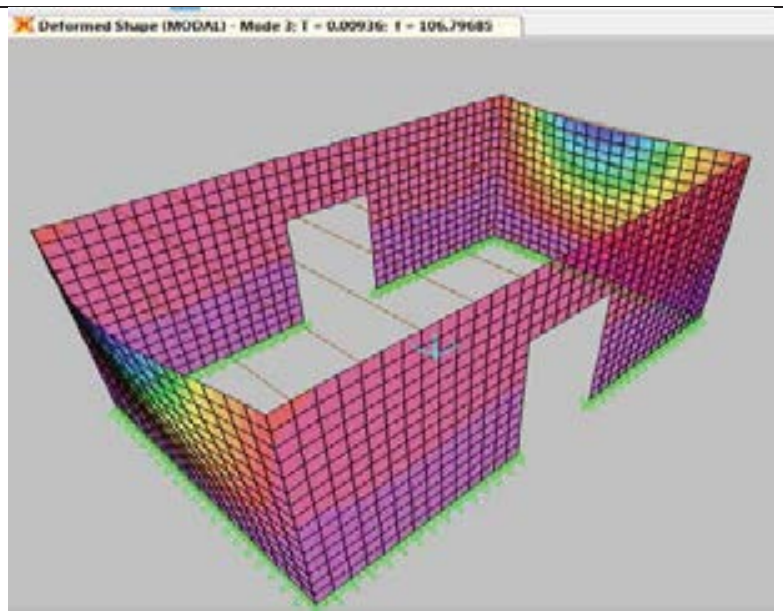

MODE 3 (1st mode in E-W direction)

Figure 2: Correlation of the first three modes of the numerical models of the prototype structure (scale 1:1) and the experimental model (scale 1:10) 


\section{EXPERIMENTAL TESTS}

\subsection{Experimental setup}

The model structure was attached at the expanded platform of the shaking table of Frederick University which can move in one direction (E-W) (figure 3). Four accelerometers were used for the recording of the base excitation $(\mathrm{CH} .1)$ and the response of the experimental model at the top of the masonry walls (CH.2, CH.3 and CH.4) (figure 4). One of them attached at the middle of the west wall (CH.2) and one at the middle of the north wall (CH.3). The last one $(\mathrm{CH} .4)$ attached at the edge of the west wall. By the evaluation of the records from this accelerometer with the one from $\mathrm{CH}$. 2, the possible torsional response or out of phase response of the model can be estimated. All these instruments were connected with the data acquisition system for the recording the signals from the excitation and the response of the model.

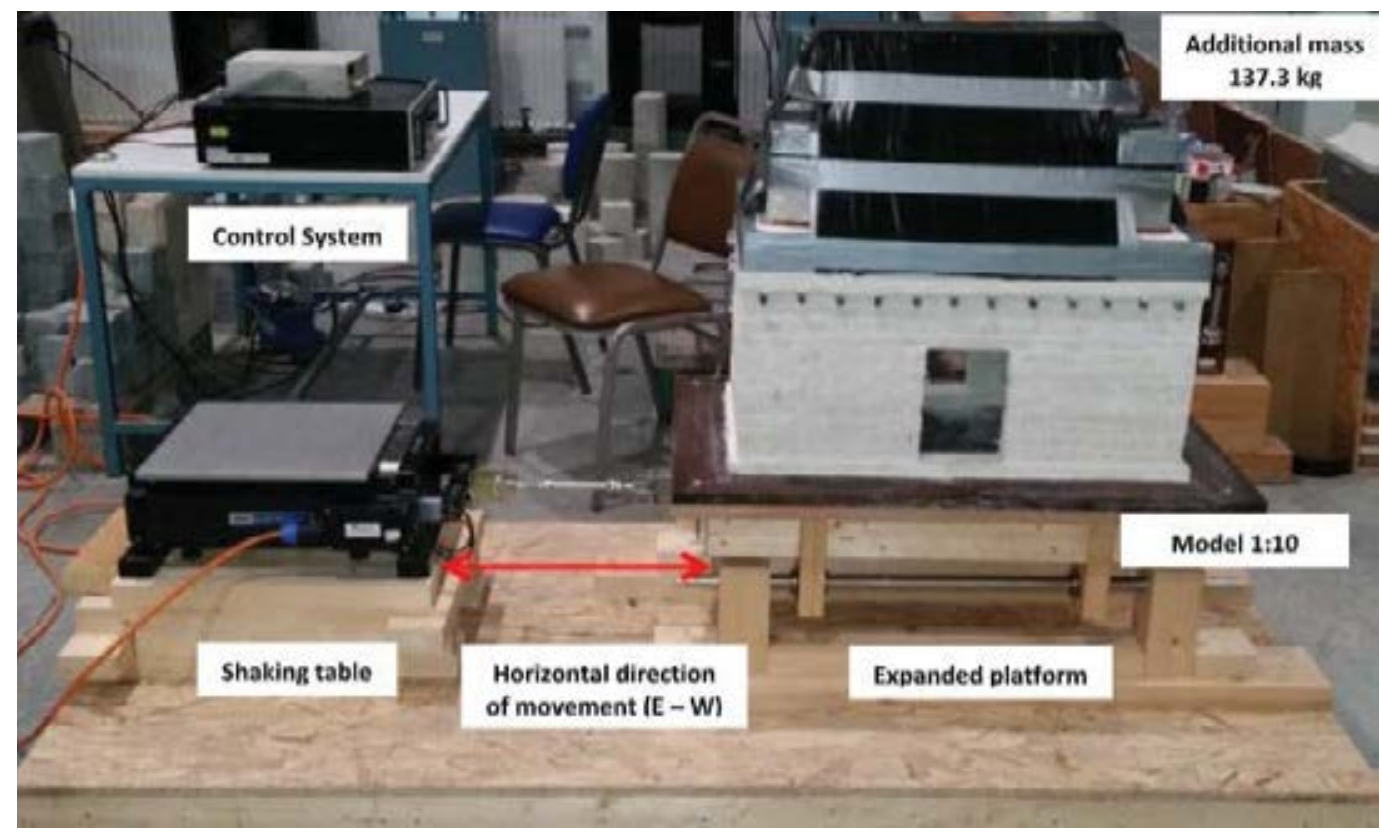

Figure 3: Experimental configuration

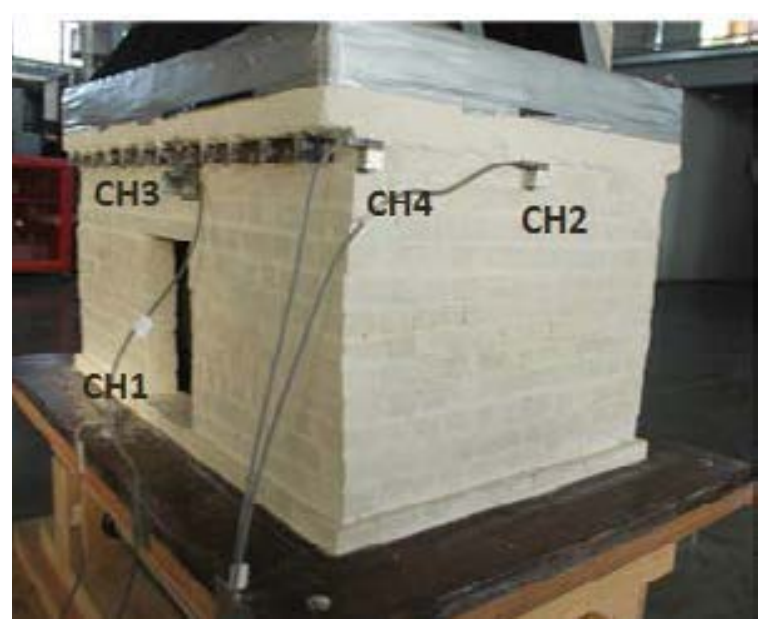

- CH1: Base Excitation

- CH2: Mid Top of West wall - (E-W)

- CH3: Mid Top of North wall - (N-S)

- $\mathrm{CH} 4$ : Edge of West Wall - (E-W)

Figure 4: Instrumentation of the experimental model 


\subsection{Sequence of the experimental tests}

The main scope of this effort is to examine the behavior of the model structure under earthquake base excitations. However, at the present investigation, the model structure was tested in various other cases with the main scope to understand its behavior under dynamic loadings. Therefore, the experimental sequence includes:

- Impulse tests for the estimation of the dynamic properties (period and viscous damping) (figure 5). However after the evaluation of these results it was founded out much differences with those from numerical simulations due to the interaction of the system with the shaking table platform. Therefore, an extended sequence of tests are under progress.

- Sinusoidal base excitations in a various range of frequencies and amplitude of the excitations but in low level to avoid the occurrence of damages

- Random white noise base excitations in various levels in order to moderate the occurrence of damages (figure 6). During these tests, damages were occurred when the max. acceleration response in $\mathrm{E}-\mathrm{W}$ direction was $0.3 \mathrm{~g}$.
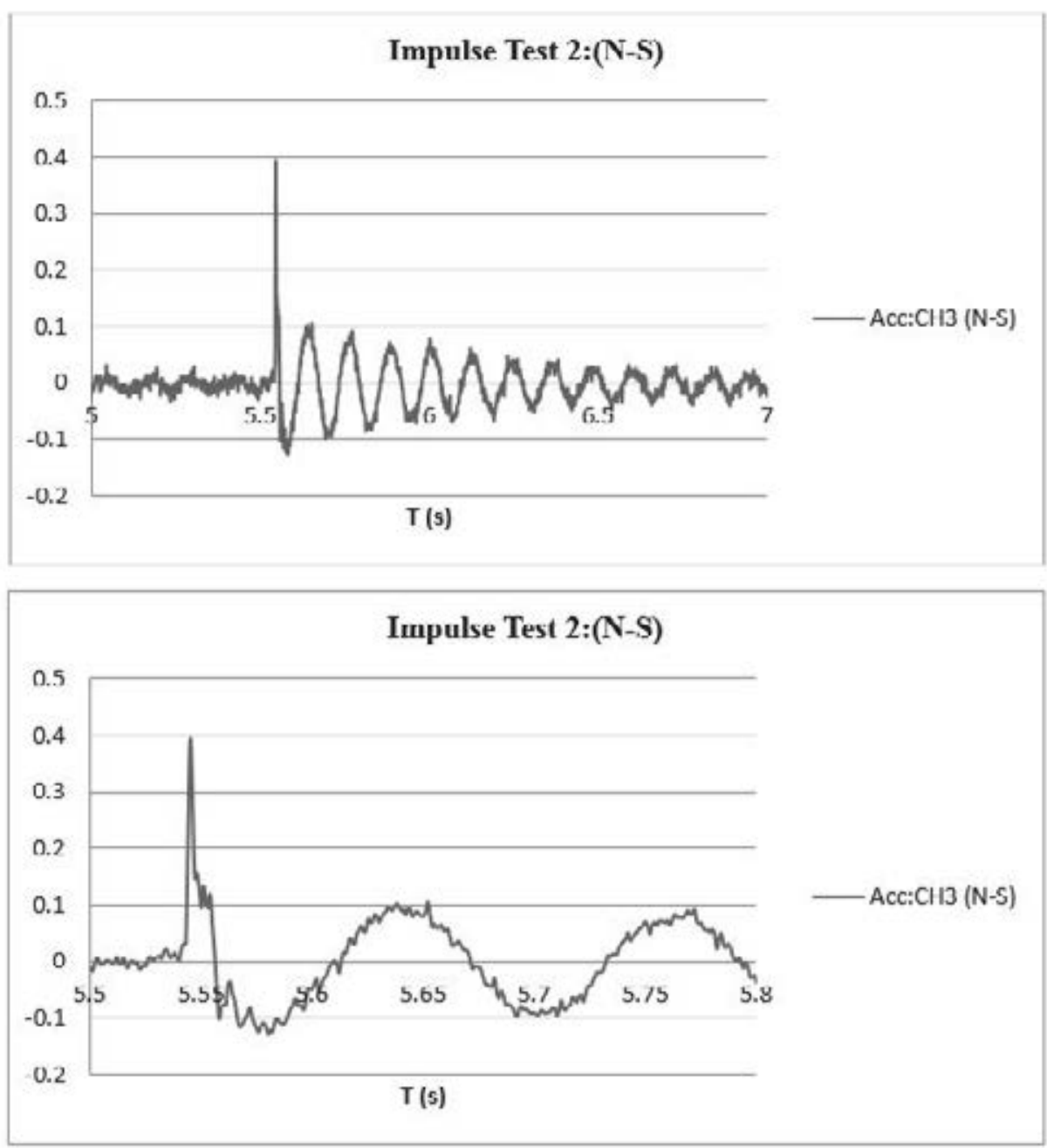

Figure 5: Acceleration records from impulse test in N-S direction 

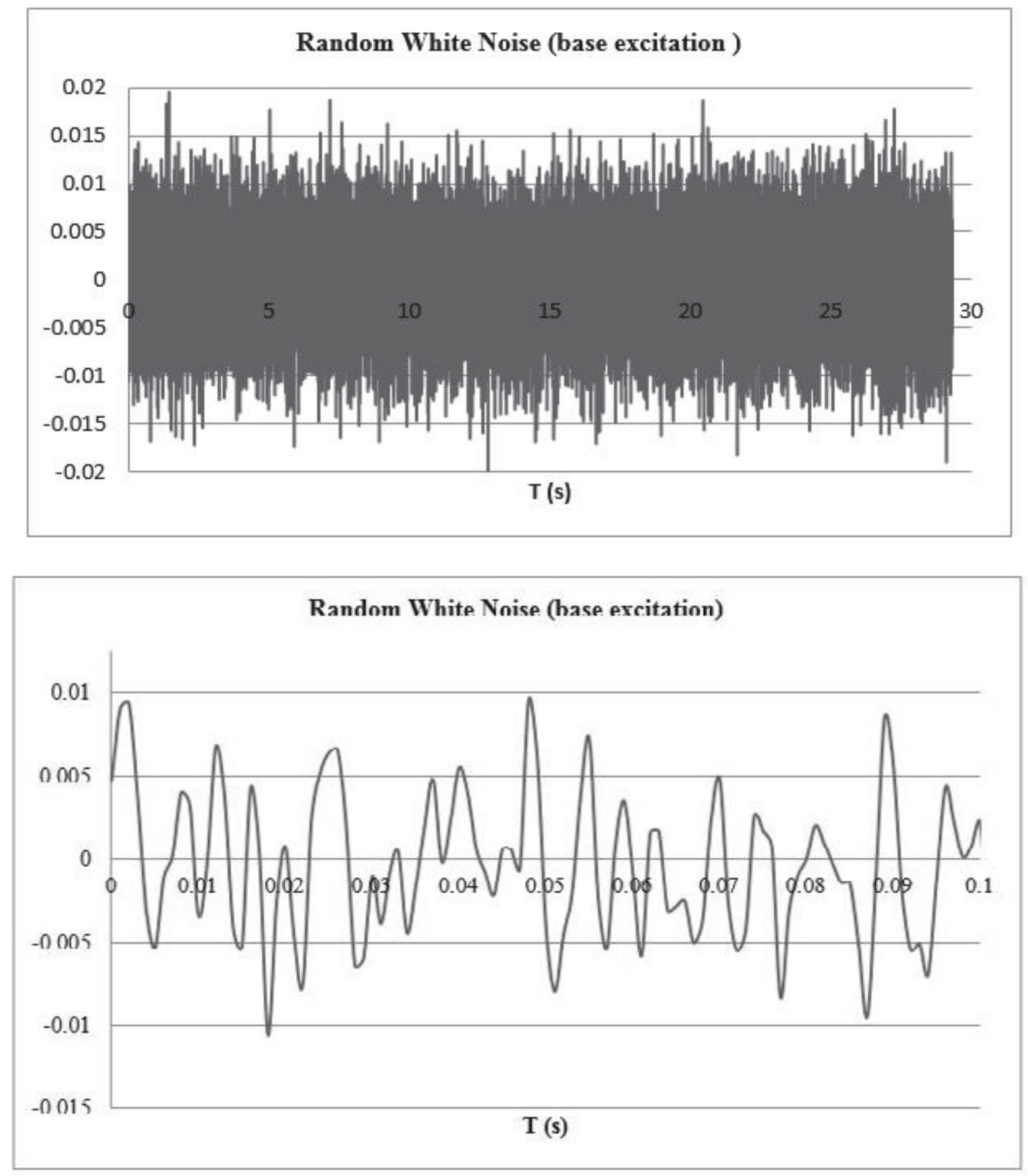

Figure 6. Base acceleration during random white noise 


\subsection{Observed damages}

As has been mentioned, during random white base excitations tests, the first damages were observed in masonry walls located in direction E-W. These damages can be divided in two groups. The first group includes cracks at the mortar joints close to the upper corners of the openings which are expanded in diagonal direction up to the roof level. The second group includes also cracks at the mortar joints at the bottom of the corners of the masonry walls (figures $7 \& 8$ ). As has been also mentioned in the previous paragraph, these cracks were observed when the max. acceleration response was $0.3 \mathrm{~g}$ in $\mathrm{E}-\mathrm{W}$ direction. However, maybe these cracks were created as micro cracks during previous lower level of acceleration response.
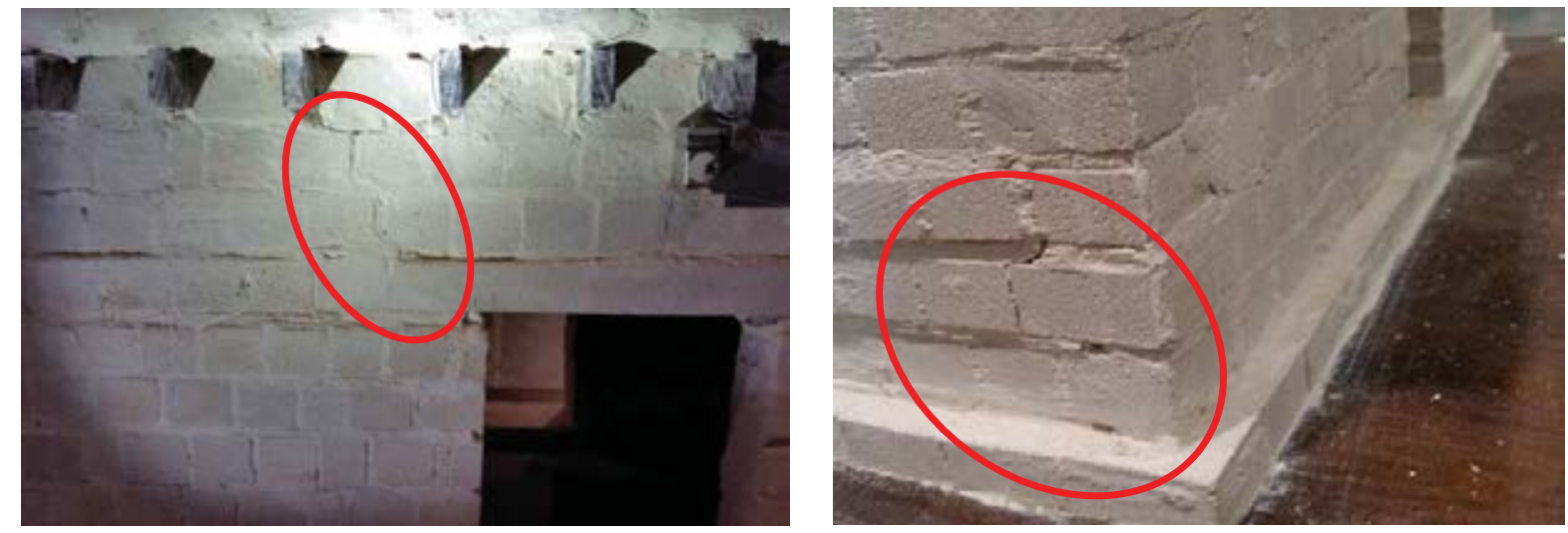

Figure 7: Observed diagonal cracks at the corner of the opening and at the bottom corner of the walls

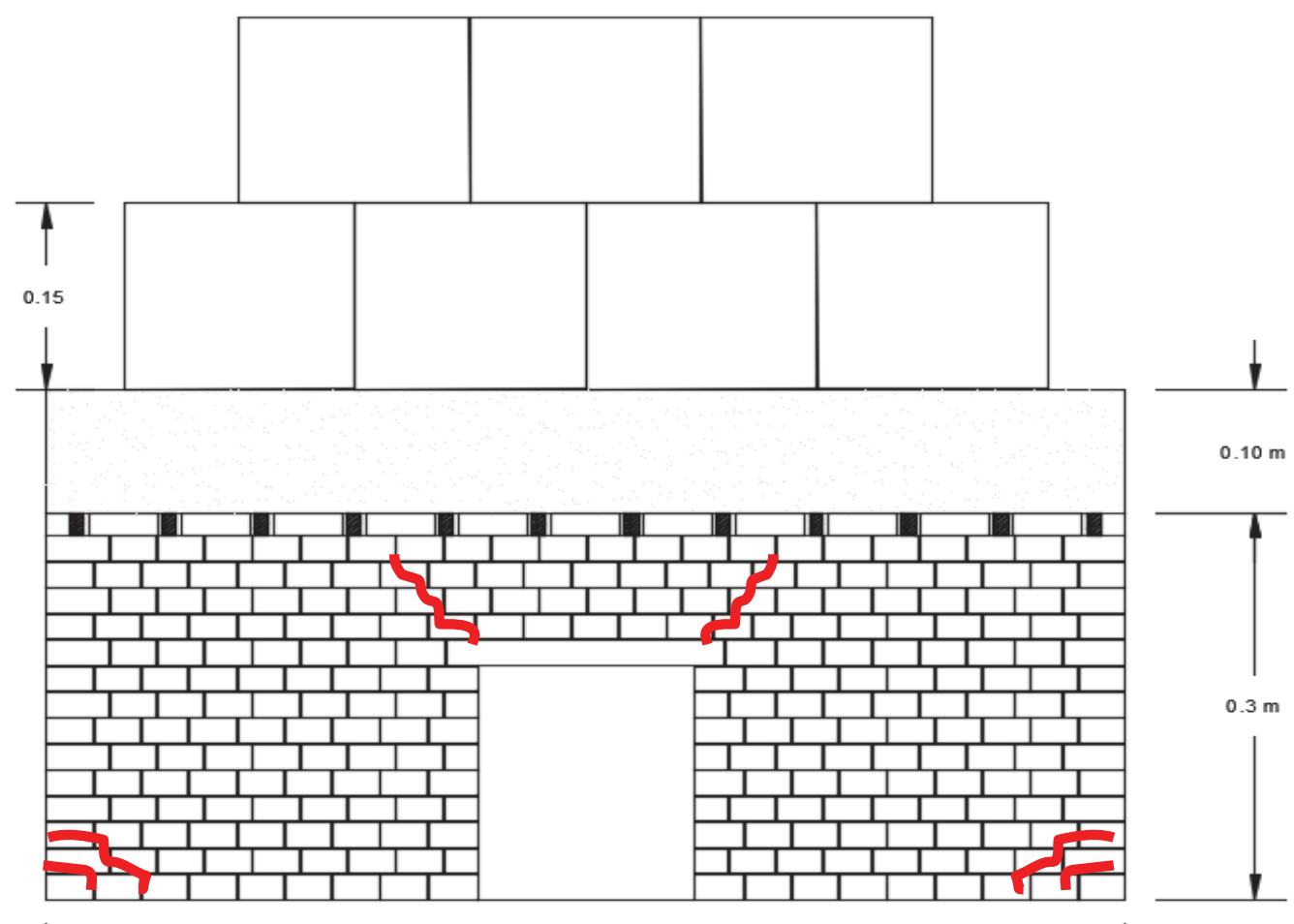

Figure 8: Location of cracks on the facade of the experimental model 


\section{NUMERICAL SIMULATIONS AND STRUCTURAL ANALYSIS}

\subsection{Simulations of loadings and structural system}

During the experimental tests it was founded out that the damages were observed when the max. response acceleration was $0.3 \mathrm{~g}$. The created loadings on the structural model were estimated through a simple method as explain in what follow (fig. 9). The horizontal seismic force (F)at the top of the masonry walls was estimated by multiply the additional masses with the max. value of the recorded acceleration. This force is distributed as horizontal load at the timber beams (fi). The horizontal force from the additional masses creates also a bending moment at the top of the masonry walls (M). The vertical loading from the additional masses $(\mathrm{N})$ is also distributed at the timber beams (Ni) in combination with those created by the bending moment (Nmi). In addition to that, horizontal loadings are created also on the masonry walls (fwi). All these loadings with the gravity load of the masonry wall were used for the study of a masonry wall in E-W direction under vertical loads and horizontal static loadings. A mesh with $2 \mathrm{cmX} 2 \mathrm{~cm}$ finite elements was used for the simulation of the masonry wall with the assumption of isotropic material using the software SAP200 (fig. 10).
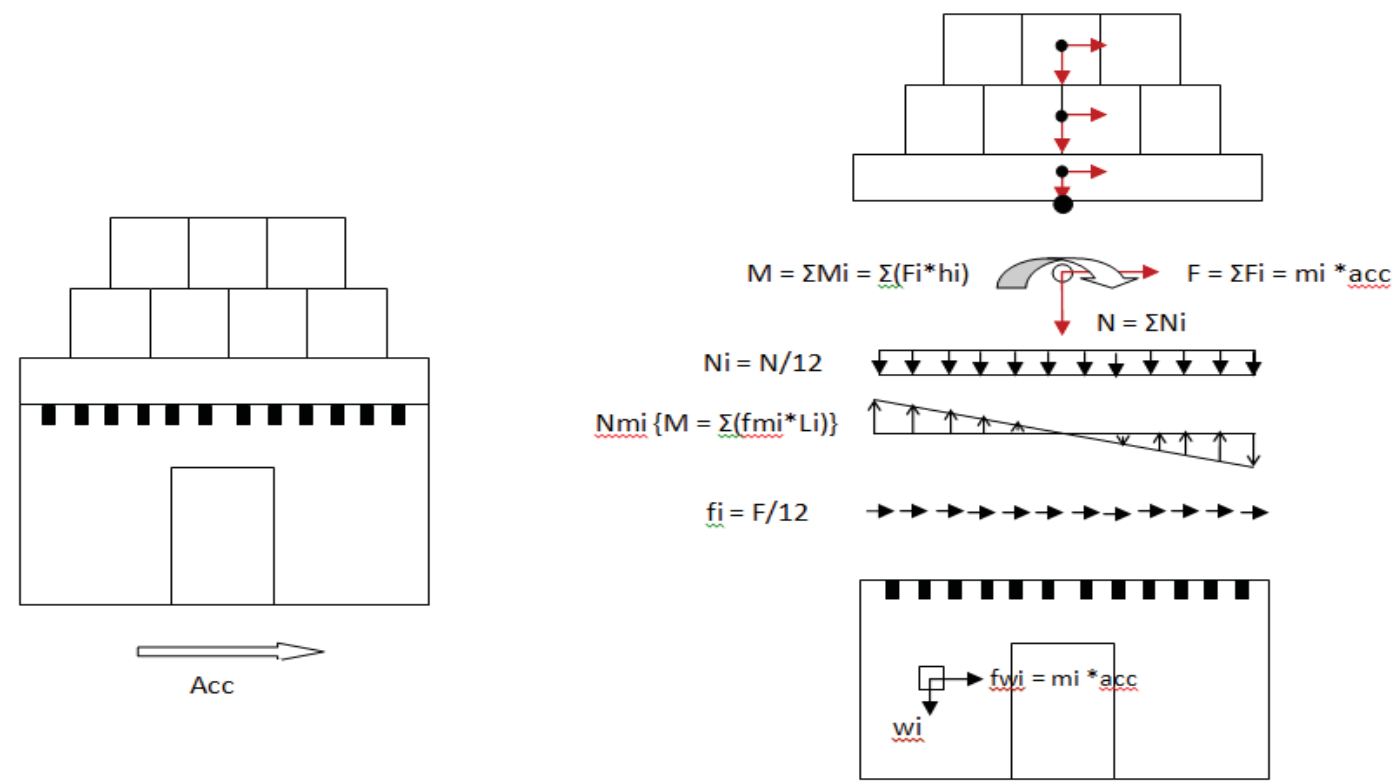

Figure 9. Estimation of the seismic loads

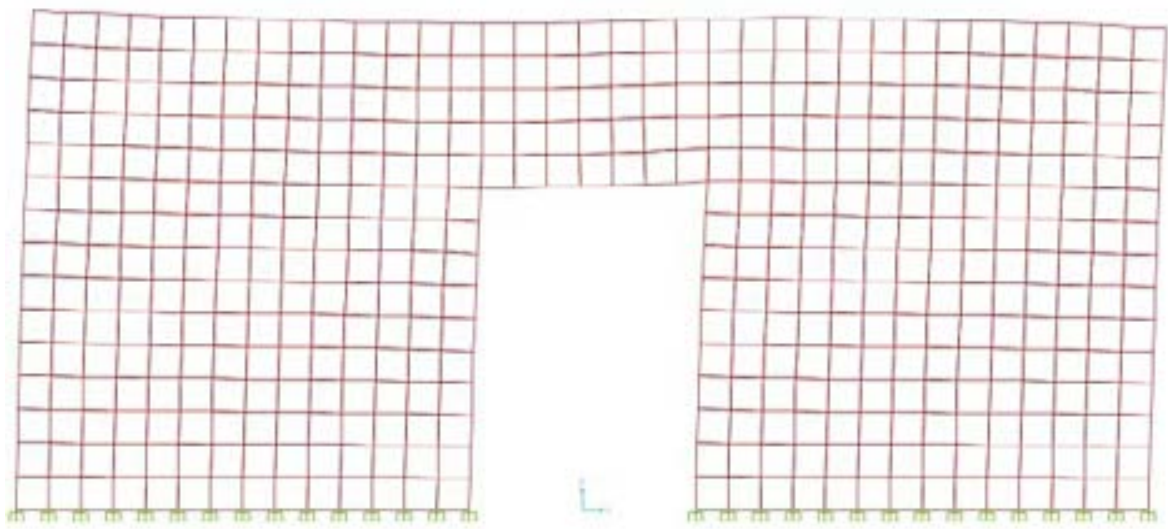

Figure 10. Numerical model under lateral seismic loadings 


\subsection{Structural analysis and evaluation of the results of the experimental model}

The vertical stresses (S22) (compression or tension) of the numerical model are shown in figure 11 as well the shear stresses (S12) in figure 12. From these figures, it can be seen that at the left bottom of the wall significant tensile stress is created however the compressive strength is in lower level in the opposite site. Exactly the opposite will be occurred if the lateral load is applied to the opposite direction. The results of the stresses (S22 \& S1) from this analysis were evaluated using Mohr - Coulomb failure criterion $(\tau-\sigma)$. For the design of the envelope of the failure criterion the tensile, the shear and the compressive strength of masonry wall were used as defined from the experimental tests. This evaluation is presented in figure 13. Each point presents the corresponding results of the of shear (S12) and normal (S22) stresses of a joint of a finite element. The points which are in outside area of the failure criterion is mean that the corresponding joint of the finite element is failed. These finite elements are colored in the mesh (figure 13). By the correlation of this mesh with the figure 8 it can be said that the numerical results are in a good agreement with the locations and the type of the observed damages during the experimental test showing only tensile mode of failures.

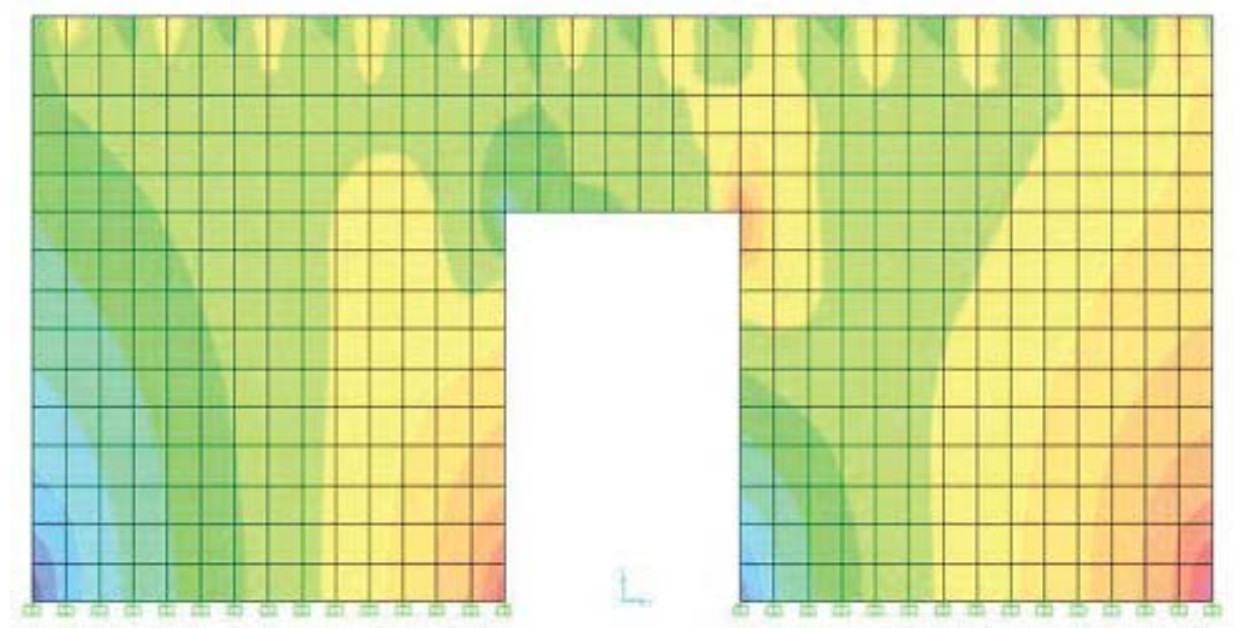

Figure 11. Vertical normal stress (S22) due to vertical and horizontal seismic loadings

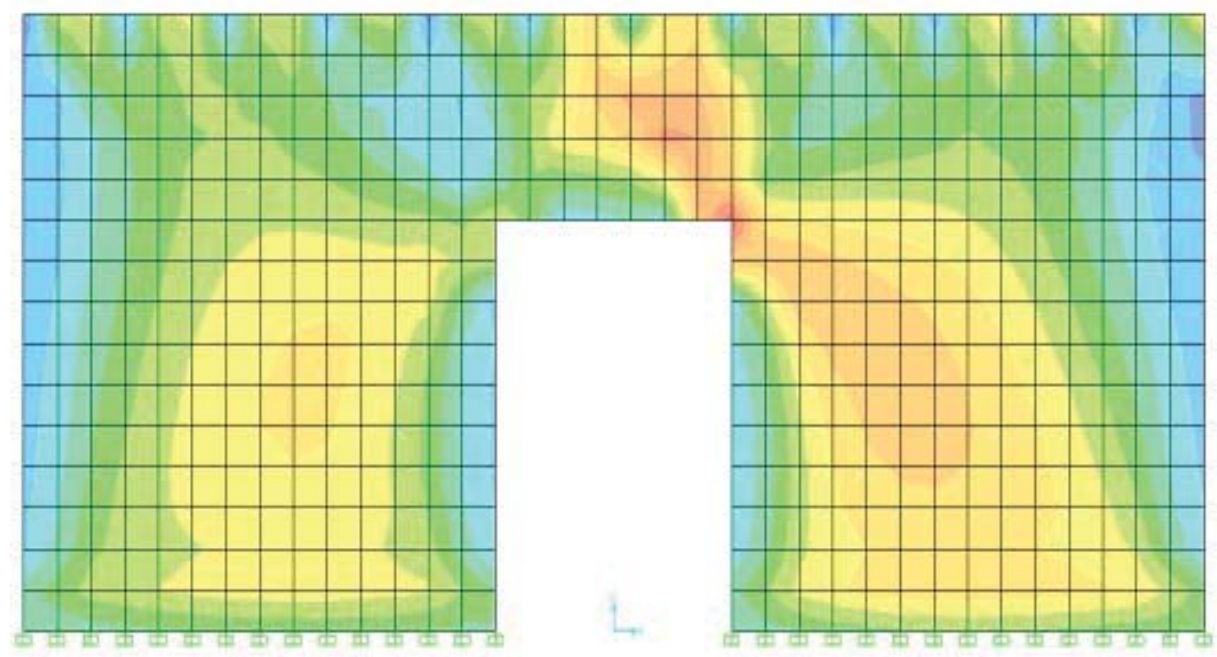

Figure 12. Shear stress (S12) due to vertical and horizontal seismic loadings 


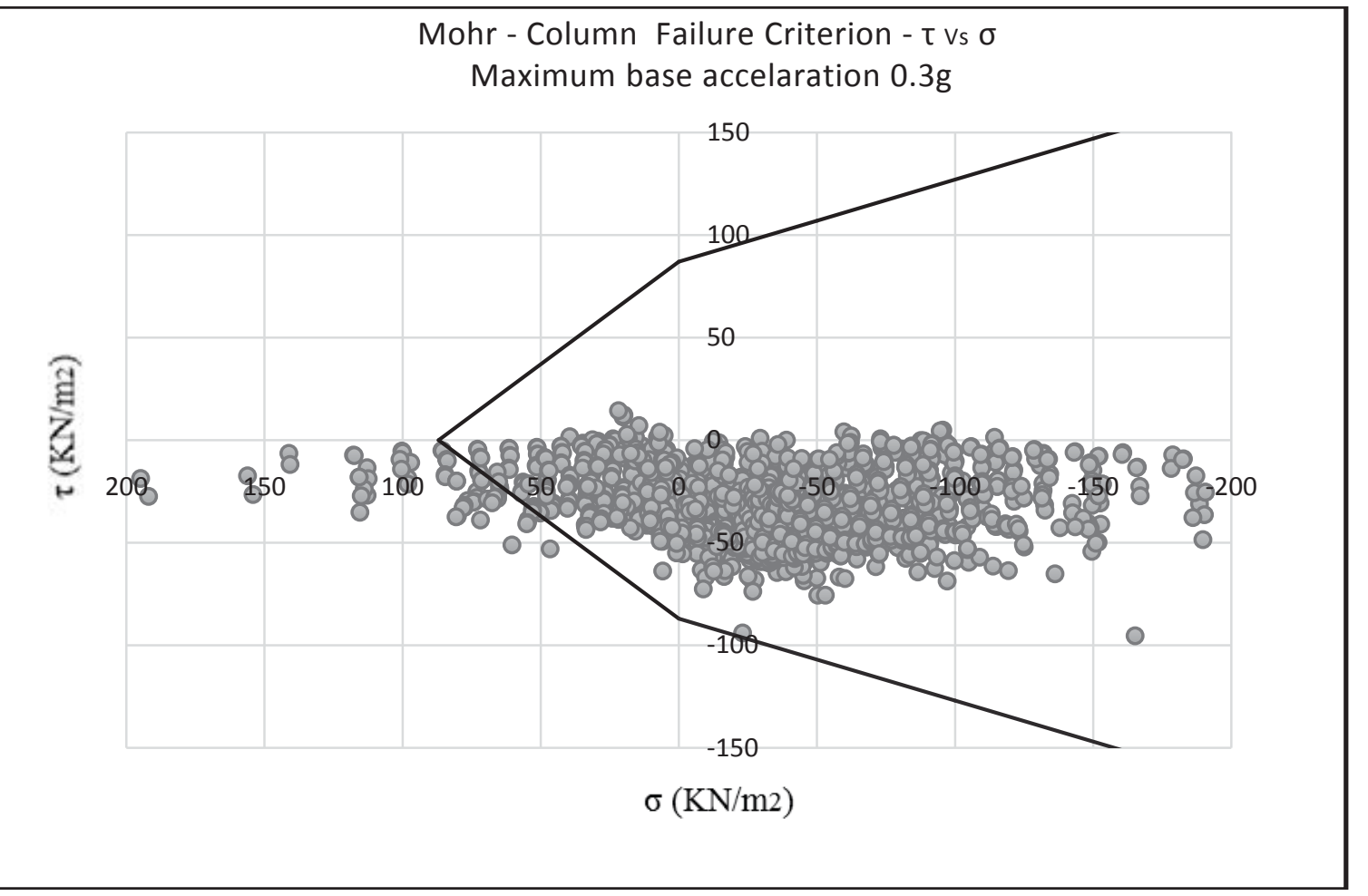

Figure 13. Mohr Column Criterion - Maximum base acceleration 0.3g

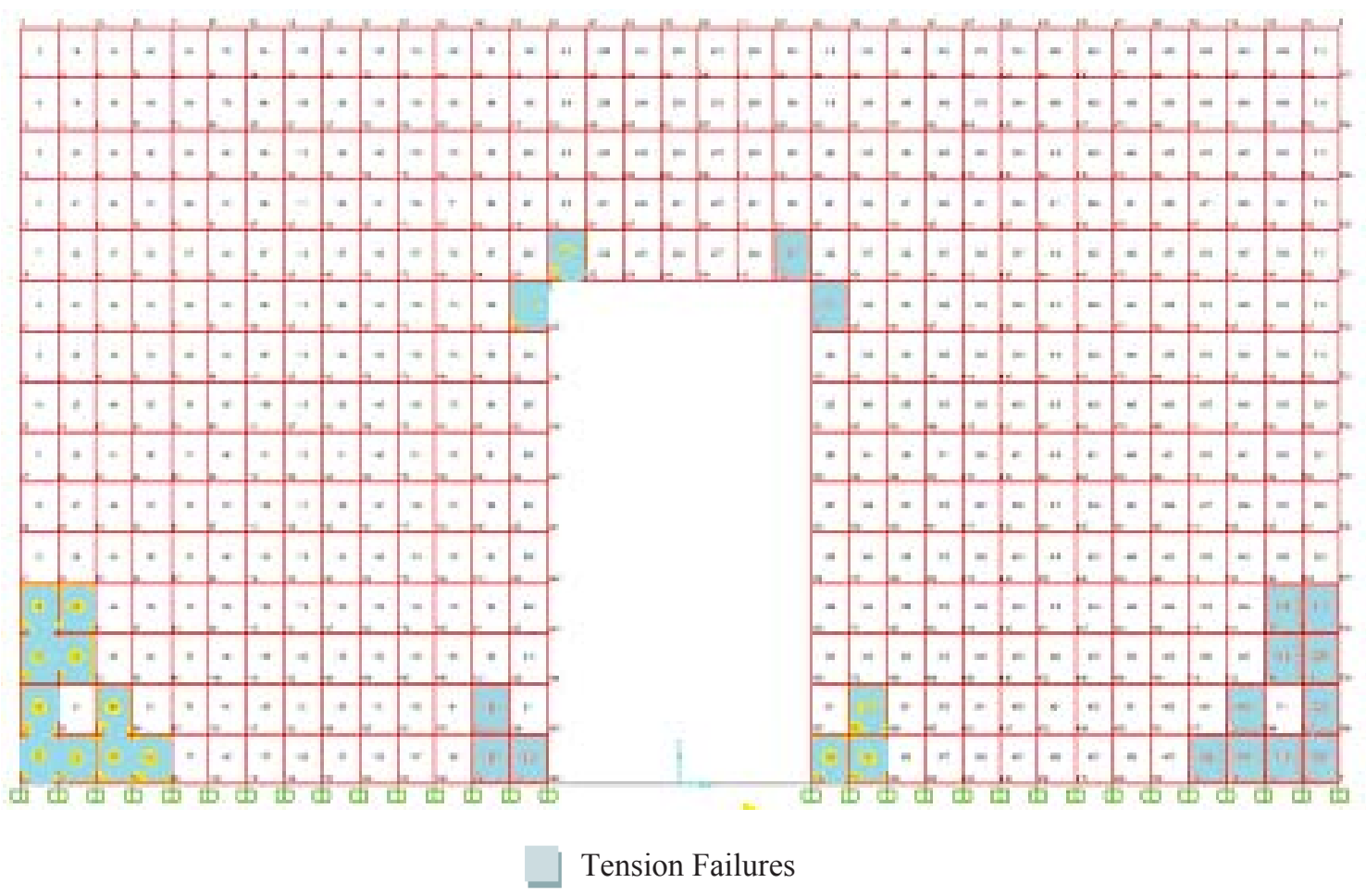

Figure 14. Evaluation of the numerical results with Mohr - Coulomb failure criterion and colored of the finite elements with failure of the experimental model (scale 1:10) 


\subsection{Structural analysis and evaluation of the results of the prototype structure}

The same procedure for the simulation of the loadings and the structural system was applied also for the prototype structure defining the max. response acceleration $0.3 \mathrm{~g}$. However this system is without additional masses therefore the loadings due to the response acceleration are created only on the roof system and the masonry walls. Although the we have the same distribution of vertical normal stresses (S22) and shear stresses (S12), the max. values of these stress were founded much higher than those developed in the case of the experimental model. Also, for the evaluation of the numerical results the Mohr - Coulomb failure criterion was used with the main scope to find the location and the type of failures.

As can be seen in figure 14, the combination of vertical normal stresses (S22) with the shear stresses (S12) of more joints of the finite elements were founded to exceed the failure criterion. On the other hand, we can see that except of the exceed of the tensile stresses there is also a significant exceeding of the shear strength at the area with lower level of normal stresses which define cracks of the joint mortars. The joints of finite elements and the corresponding finite elements with exciding of the level of stresses defined by the envelope of the failure criterion are colored in the mesh (figure 14). By this figure we can see that the tensile failures on the numerical model of prototype structure are in a good agreement with those occurred on the numerical model of the experimental model. However, and in addition to that as have been mentioned above, shear failures are founded out especially in an horizontal line at the bottom of the wall which can be characterized as sliding mode failures, as well the initiation of diagonal cracks can be mentioned.

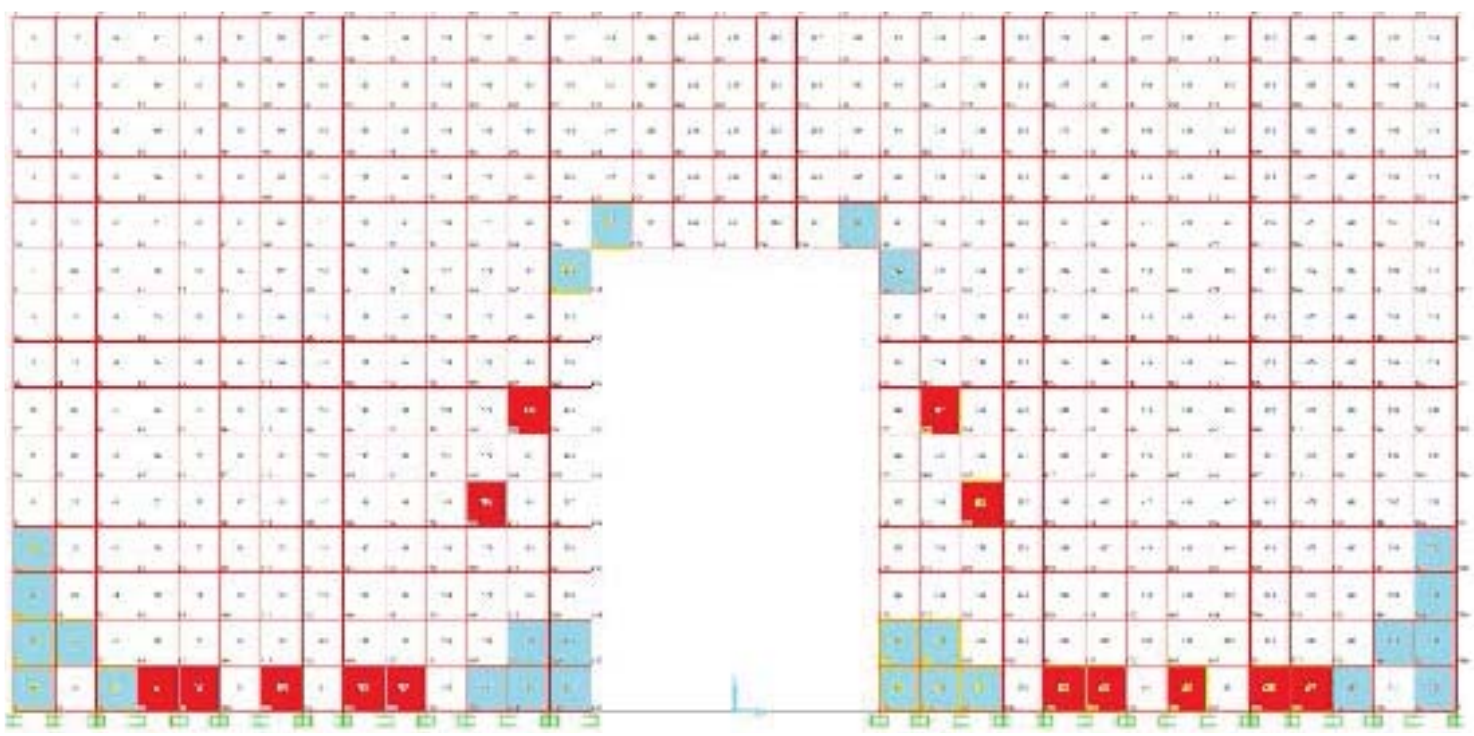

Shear Failures

Tension Failures

Figure 15. Evaluation of the numerical results with Mohr - Coulomb failure criterion and colored of the finite elements with failure of prototype structure (scale 1:1) 


\section{CONCLUSIONS}

Through this effort, a simple masonry building (prototype building in scale 1:10) was designed and at the same time an experimental model building was designed and constructed in scale 1:10 of the prototype building. Specific rules were adopted for that focused on the modal analysis results, the distribution of stresses under vertical loadings and the level of the tensile stresses. The experimental model was subjected in various base excitations using the shaking table of Frederick University. However, before the design and the construction of the experimental model, the mechanical properties of the used materials (stone, mortar, masonry and timber) were defined through experimental tests. The scopes of this effort was:

Firsts, to validate the numerical results from the structural analysis of the experimental model with those from the experimental tests, focus on the correlation of the type and the location of the observed damages, using the Mohr - Coulomb failure criterion for the evaluation of the numerical results. which designed according to the mechanical properties of the used materials. From this point of view it was found out enough good correlation between the experimental and numerical results which both of them developed only bending modes of failures by the exceeding of the tensile strength.

Second, the numerical results of the experimental model (in scale 1:10) to be able to reproduce similar behavior of the prototype one (in scale 1:10), again focus on the observed location and type of damages. From this point of view it can be said that it was founded out differences between two numerical models. Although, in both of them were founded out tensile mode of failures at the same locations of the numerical models, the model of prototype structure developed also shear failures. Due to that, the quantity and the effectiveness of the additional masses applied to the experimental must be checked and resigned.

\section{REFERENCES}

[1] G.C. Manos, V. Soulis, J. Thawabteh, 2003, "Numerical Investigation of Mortar - Joint Modes of in-plane failure Utilizing Unereinforced Masonry Assemblages", 9th North American Masonry Conference, Clemson Univ., North Carolina, USA

[2] G.C. Manos, V.J. Soulis, J. Thawabteh, 2003 "Non-linear Numerical Simulation of the Mortar Joints' Failure Mechanism Utilizing Unreinforced Masonry Assemblages", 6th Intern. Symp. on Computer methods in Str.1 Masonry, Italy.

[3] Paulo Candeias, A. Campos Costa, Ema Coelho, 2004, "Shaking table tests of 1:3 reduced scale models of four story unreinforced masonry buildings", 13th World Conference on Earthquake Engineering Vancouver, B.C., Canada

[4] Lakshmi Keshav, and V. G. Srisanthi, 2012, Masonry CSEB Building Models under Shake table Testing-An Experimental Study,World Academy of Science, Engineering and Technology, International Journal of Civil and Environmental Engineering Vol:6, No: 12

[5] S. Demosthenous, 2016, Experimental and Numerical Investigation of a Masonry Model Building Structure in scale 1:10, Final Year Project, Dept. of Civil Engineering, Frederick University, Supervisor, M. Demosthenous 